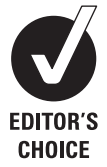

1Division of Primary Care, University of Nottingham, Nottingham, UK ${ }^{2}$ NHS Nottinghamshire County, Birch House Ransom Wood Business Park, Mansfield, Nottinghamshire, UK

${ }^{3}$ Glasgow Housing Association, Glasgow, UK

${ }^{4}$ School of Health and Social Care, University of the West of England (Bristol) Frenchay Campus, Coldharbour, UK

${ }^{5}$ Child Accident Prevention Trust, Canterbury Court, London, UK

${ }^{6}$ East End Child Safety Project, Glasgow, UK

${ }^{7}$ City Building Glasgow LLP, Milton Service Centre, Glasgow, UK

${ }^{8} \mathrm{NHS}$ Greater Glasgow and

Clyde, Dalian House,

Glasgow, UK

Institute for Health Research Swansea University,

Swansea, UK

${ }^{10}$ East End Community Homes, Forge Shopping Centre, Glasgow, UK

\section{Correspondence to} Professor D Kendrick Division of Primary Care, 13th Floor, Tower Building, University of Nottingham, Nottingham NG7 2RD, UK denise.kendrick@nottingham. ac.uk

Accepted 25 April 2010 Published Online First 16 June 2010

\title{
Randomised controlled trial of thermostatic mixer valves in reducing bath hot tap water temperature in families with young children in social housing
}

\author{
D Kendrick, ${ }^{1}$ J Stewart, ${ }^{2}$ S Smith, ${ }^{1}$ C Coupland, ${ }^{1}$ N Hopkins, ${ }^{3}$ L Groom, ${ }^{1}$ E Towner, ${ }^{4}$ \\ M Hayes, ${ }^{5}$ D Gibson, ${ }^{3}$ J Ryan, ${ }^{6}$ G O'Donnell, ${ }^{7}$ D Radford, ${ }^{8}$ C Phillips, ${ }^{9}$ R Murphy ${ }^{10}$
}

\begin{abstract}
Objectives To assess the effectiveness of thermostatic mixing valves (TMVs) in reducing bath hot tap water temperature, assess acceptability of TMVs to families and impact on bath time safety practices.

Design Pragmatic parallel arm randomised controlled trial.

Setting A social housing organisation in Glasgow, Scotland, UK.

Participants 124 families with at least one child under 5 years.

Intervention A TMV fitted by a qualified plumber and educational leaflets before and at the time of TMV fitting.

Main outcome measures Bath hot tap water temperature at 3-month and 12-month post-intervention or randomisation, acceptability, problems with TMVs and bath time safety practices.
\end{abstract}

Results Intervention arm families had a significantly lower bath hot water temperature at 3-month and 12-month follow-up than families in the control arm (3 months: intervention arm median $45.0^{\circ} \mathrm{C}$, control arm median $56.0^{\circ} \mathrm{C}$, difference between medians, -11.0 , $95 \% \mathrm{Cl}-14.3$ to -7.7$) ; 12$ months: intervention arm median $46.0^{\circ} \mathrm{C}$, control arm median $55.0^{\circ} \mathrm{C}$, difference between medians $-9.0,95 \% \mathrm{Cl}-11.8$ to -6.2 ) They were significantly more likely to be happy or very happy with their bath hot water temperature (RR 1.43, 95\% Cl 1.05 to 1.93), significantly less likely to report the temperature as being too hot (RR $0.33,95 \% \mathrm{Cl} 0.16$ to 0.68) and significantly less likely to report checking the temperature of every bath (RR $0.84,95 \% \mathrm{Cl} 0.73$ to 0.97). Seven (15\%) intervention arm families reported problems with their TMV.

Conclusions TMVs and accompanying educational leaflets are effective at reducing bath hot tap water temperatures in the short and longer term and are acceptable to families. Housing providers should consider fitting TMVs in their properties and legislators should consider mandating their use in refurbishments as well as in new builds.

\section{INTRODUCTION}

Approximately 2000 emergency department attendances and 500 hospital admissions following bath water scalds to children occur in the UK each year. ${ }^{1}$ Admissions mostly occur in children aged under 5 years, often involving prolonged inpatient stays, transfer to a specialist hospital or burns unit. ${ }^{1}$ The cost of treating a severe scald has been estimated at $£ 250<\mathrm{TS}$, thin space here $>000{ }^{1}$

\section{What is already known on this topic}

- Hot bath water scalds are an important public health problem; their incidence has not declined over recent years.

- Thermostatic mixing valves (TMVs) have the potential to reduce scald risk but there have been no randomised controlled trials assessing their effectiveness and acceptability to families.

\section{What this study adds}

- TMVs and educational leaflets are effective in reducing bath hot tap water temperature in the short and longer term and are acceptable to families.

- Families with TMVs are less likely to check bath water temperature. The importance of checking temperature should be emphasised during TMV fitting and further research should explore ways of increasing such safety practices.

Longer-term effects include disability, disfigurement or psychological harm.

Children from disadvantaged areas ${ }^{2}$ and younger children are at greater risk of scalds. ${ }^{3}$ Commonly bath water scalds happen when children fall or climb unsupervised into water; a child turns on the hot tap or a parent puts a child into water that is too hot. ${ }^{14}$ Home water thermostats are frequently set at $60^{\circ} \mathrm{C}$ or above. ${ }^{5}$ Water at this temperature can cause a full thickness burn in an adult in 5 seconds, ${ }^{1}$ and more quickly in children. ${ }^{6}$ It is recommended that the bath hot tap water temperature should not exceed $46^{\circ} \mathrm{C} .^{7}$

Early studies offering educational interventions to promote tap water temperature testing and/or thermostat reduction demonstrated at best a small effect on tap water temperatures, often reducing them insufficiently to reduce the risk of scalds ${ }^{8-11}$ A recent meta-analysis of home 
safety interventions, most of which comprised education and providing equipment to prevent a range of childhood home injuries, found a significant reduction in water temperatures; but again, in most studies the temperature post-intervention remained above current recommended levels. ${ }^{12}$ Legislation to reduce thermostat settings has been more successful with uncontrolled studies demonstrating reductions in hospital admission rates, total body area burnt, scarring and skin grafting. 13

Thermostatic mixing valves (TMVs) are designed to reduce the risk of scalding from hot tap water. They do not affect the temperature of stored hot water or interfere with heating systems and allow hotter water to be supplied to different sites within the home. They fit across bath hot and cold water supply pipes and set the hot tap water at a fixed temperature, regardless of changes in pressure or temperature in the water supply system. As the bath water supply pipes are usually housed behind bath panels, they are not easily accessible by families. Although families could theoretically adjust their $\mathrm{TMV}$, its positioning would make this difficult. The English government recently announced amendments to building regulations requiring $T M V$ s to be fitted in new build properties, extensions and buildings converted to dwellings. ${ }^{14}$ However, TMVs have not been tested for effectiveness and acceptability in the domestic setting in the UK, and importantly effectiveness has not been tested in a high-risk population. We have therefore conducted a randomised controlled trial in deprived communities in Glasgow. ${ }^{15} 16$

\section{METHODS \\ Design}

Pragmatic (ie, designed to measure the benefit of the intervention in normal practice) parallel arm randomised controlled trial.

\section{Participants}

Generalisabilty was maximised using broad inclusion and minimal exclusion criteria.

Families with children under 5 years living in Glasgow Housing Association (GHA) housing (Europe's largest social housing provider) were eligible for inclusion. Exclusion criteria were moving from the property, pipe work unsuitable for TMV fitting and participation in other tap water scald prevention projects.

Recruitment was by written invitation from GHA to tenants on the East End Child Safety Project database, which is a database of families who have taken part in a previous child safety project and to tenants aged 18-40 years identified from the GHA tenant database; or by face-to-face contact with local housing organisations. Families were randomised to intervention or control arms. The intervention comprised:

- A study specific educational leaflet mailed before TMV fitting, providing information on how bath water scalds happen, the time taken for scalds to occur at different temperatures, usual bathing temperatures, what a TMV is and a true story of a 2 -year-old child scalded from hot bath water.

- A TMV set at a maximum temperature of $45^{\circ} \mathrm{C}$ fitted by a qualified plumber from City Building (Glasgow) limited liability partnership (LLP). Fitting usually involved removing the bath panel, connecting the TMV to hot and cold water supply pipes and replacing the bath panel; and
- A waterproof guide was hung on the tap by the plumber. This provided information about running a bath with a TMV fitted, reiterated some information on the leaflet and advice to continue checking the temperature of bath water and not to leave children alone in the bath.

Families randomised to the control arm were offered the intervention after collection of follow-up data.

\section{Objectives}

The objectives were to assess the effectiveness of TMVs in reducing bath hot tap water temperature; acceptability of TMVs to families and impact on bath time safety practices.

\section{Definition of primary and secondary outcome measures}

The primary outcome measure was bath hot tap water temperature at 3-month and 12-month post-TMV fitting (intervention arm) or post-randomisation (control arm) considered to be the outcome of most interest to policymakers. Secondary outcomes for the intervention arm included TMV problems (eg, failures, replacements), adjustment of TMV settings and satisfaction with TMVs and fitting process. Secondary outcomes for both arms included bath hot tap water temperature $\leq 46^{\circ} \mathrm{C}$, satisfaction with bath hot tap water and bath time safety practices, chosen to reflect relevance to housing providers, families with young children and policymakers. They were measured 12-month post-TMV fitting and 12-month post-randomisation

\section{Baseline data}

Baseline data, collected by postal or telephone questionnaire, included sociodemographic and economic characteristics, bath time safety practices and satisfaction with hot water supply. Families were offered incentives (free bath mat or first aid kit) to increase response rates for the baseline questionnaire. ${ }^{17}$ GHA reported that accessing the homes of their tenants was difficult, often requiring multiple attempts. In view of this, families were offered a $£ 10$ gift voucher for use in local stores on completion of a water temperature measurement and we planned to ask participants to only have one water temperature measurement during the study, with the first $50 \%$ recruited to each arm selected for baseline measurements. A qualified plumber from City Building (Glasgow) LLP measured temperatures using a Type $\mathrm{K}$ thermocouple thermometer and rounded immersion probe. The bathroom sink hot water temperature was also measured to detect other methods of reducing water temperature-for example, reducing thermostat settings.

\section{Follow-up data}

\section{Primary outcome measure}

Families who had not been selected for a baseline temperature measurement were randomly assigned, by treatment arm, to 3-month or 12-month water temperature measurements, using a random number list. ${ }^{18}$ Where plumbers repeatedly visited homes but were unable to find anyone at home (hereafter referred to as unable to access property), families who had had a baseline measurement were selected at random for a follow-up temperature measurement, until measurements were obtained on at least 15 families, at each follow-up time point, in each arm. Families were offered a $£ 10$ gift voucher for use in local stores on completion of a water temperature measurement. 


\section{Secondary outcome measures}

Data were collected by postal or telephone questionnaire and a $£ 5$ gift voucher was offered to families on completion of the follow-up questionnaire to increase response rates. Problems with TMVs were also ascertained from repair requests or complaints made to GHA.

\section{Sample size}

Ten families per arm were required to detect a reduction in the mean bath hot tap water temperature from $60.4^{\circ} \mathrm{C}(\mathrm{SD}$ $\left.9.1^{\circ} \mathrm{C}\right)^{19}$ in the control arm to the recommended temperature of $46^{\circ} \mathrm{C} 20$ in the intervention arm $(90 \%$ power, two-sided $5 \%$ significance level). However, baseline measurements indicated a larger SD than this in the control arm (mean $60.8^{\circ} \mathrm{C}$, $\mathrm{SD} 10.25^{\circ} \mathrm{C}$ ) and temperatures immediately after valve fitting were not normally distributed with a very small SD (mean $45.5^{\circ} \mathrm{C}, \mathrm{SD} 0.51^{\circ} \mathrm{C}$ ). The sample size was therefore recalculated based on reducing mean temperature from $60.8^{\circ} \mathrm{C}$ to $46^{\circ} \mathrm{C}\left(\mathrm{SD} 10.25^{\circ} \mathrm{C}\right),(90 \%$ power, two-sided $5 \%$ significance level), assuming the asymptotic relative efficiency of the Mann-Whitney $U$ test relative to the test is never lower than 0.864. ${ }^{21}$ Under these assumptions 14 families per arm were required. Random sampling continued until measurements were achieved from 15 families in each arm at 3 months and 12 months.

For secondary outcome measures, 50 families per arm provided $80 \%$ power at the $5 \%$ significance level (two-sided) to detect a difference in the proportion of families satisfied with their water temperature from $90 \%$ in the control arm to $67 \%$ in the intervention arm. Fifty families in the intervention arm provided $80 \%$ power (one-sided $5 \%$ significance) to test the hypothesis that the proportion of TMVs removed, disabled or adjusted did not exceed $6.5 \%$ if the true proportion removed, disabled or adjusted was $1 \%$. To allow for losses to follow-up, recruitment aimed for a total of 120 participants.

\section{Randomisation}

The trial statistician used Stata ${ }^{22}$ to generate the randomisation schedule with a permuted block design and random block size. Equal numbers of consenting families were allocated to arms. No stratification was used. Allocations were placed in sequentially numbered, opaque, sealed envelopes, which were opened by an independent researcher.

\section{Blinding}

It was not possible to blind participants, plumbers or researchers to treatment arm allocation. The analysis was undertaken blind to allocation, but the analyst correctly guessed allocation for $100 \%$ and $84 \%$ of cases at 3 months and 12 months, respectively.

\section{Withdrawals}

Participants were free to withdraw from the trial at any stage. Data were included in the analyses up to the point of withdrawal.

\section{Statistical methods}

Data were double entered into an Access database with discrepancies identified and corrected. Conforming to a prespecified analysis plan, participants were analysed in the group they were randomised to regardless of the intervention received. Bath hot tap water temperatures were described using medians and IOR. The primary analysis compared temperatures between treatment arms using the Mann-Whitney $\mathrm{U}$ test and estimated the difference between median values and $95 \%$ CI around the difference using the Bonett-Price CI method. These analyses were based on families with follow-up temperature measurements. Two sensitivity analyses were undertaken. First, where families had missing follow-up temperatures, we assumed there had been no change from baseline and follow-up temperatures were replaced with the baseline temperature for that family, or where baseline temperatures were unavailable, with the median baseline temperature for that treatment arm. Second, as the potential for temperature reduction depended on the baseline temperature, we adjusted for baseline temperatures (or median treatment arm temperature if baseline temperature was missing) by calculating change scores.

Secondary outcomes were compared between treatment arms by estimating relative risks and $95 \%$ CI. Where the prevalence of outcomes at baseline differed between treatment arms by more than $10 \%$, we estimated the Mantel-Haenszel adjusted relative risk and $95 \% \mathrm{CI}$.

\section{Ethical and organisational approval}

Ethics committee review was undertaken by Nottingham 1 NHS Research Ethics Committee. Organisational approval was gained from NHS Nottinghamshire County

\section{RESULTS}

\section{Participant flow and follow-up}

The flow of participants is shown in figure 1. In all, 124 participants were randomised. Data on participants excluded after randomisation and collection of baseline data on those who withdrew are included in the analysis of baseline data. ${ }^{23}$ Losses to follow-up and the reasons for loss to follow-up are given in figure 1 .

Baseline questionnaire data were collected between June 2006 and January 2007, with TMV fitting and temperature measurements undertaken between July 2006 and February 2007. The median time between recruitment and baseline temperature measurement was 59.5 days in the intervention arm and 48 days in the control arm. Three-month temperatures were collected between February and April 2007, follow-up questionnaire data between August 2007 and April 2008 and 12-month temperatures between November 2007 and April 2008. The median time between TMV fitting and 12-month temperature measurement in the intervention arm was 467 days and between randomisation and 12 -month temperature measurement in the control arm was 449 days.

\section{Analysis}

Participants' characteristics are shown in table 1 and baseline description of hot water temperature, satisfaction and bath time safety practices in table 2 . Control arm participants were more likely to live in single adult households and run baths using cold water first and less likely to have left children alone in the bath or bathroom while the bath was running. The median bath hot tap water temperature in the intervention arm at baseline was $55^{\circ} \mathrm{C}\left(\operatorname{IQR} 54-58^{\circ} \mathrm{C}\right)$ and $58^{\circ} \mathrm{C}$ (IQR $55-62^{\circ} \mathrm{C}$ ) in the control arm. Most families were happy with their bath hot water temperature and described it as very hot. All those unhappy with the temperature, 


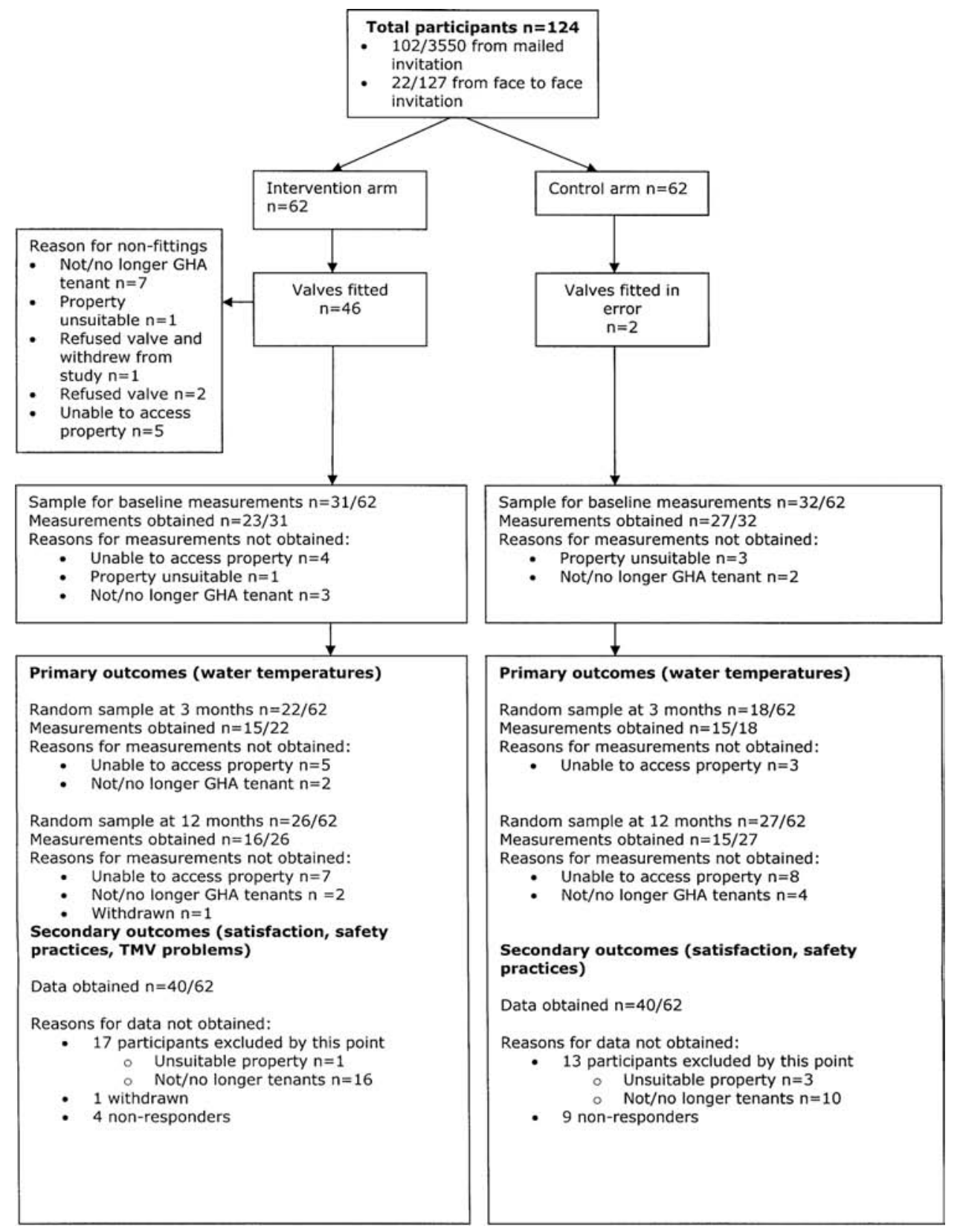

Figure 1 Flow of participants through trial. GHA, Glasgow Housing Association.

described it as hot/very hot. Water temperatures, the infrequent use of cold water first when running the bath and the number of families leaving children alone in the bath or bathroom suggests a considerable proportion of families were at risk of scalds.

Figure 2 shows the distribution of bath hot tap water temperatures in the two groups at baseline, and at 3 months and 12 months. Table 3 shows that at both follow-up time points during follow-up, bath hot tap water temperatures were significantly lower in the intervention than in the control arm. Findings were robust to adjusting for baseline tap water temperature and to replacing missing temperatures with baseline values. There was no significant difference in bathroom sink hot tap water temperatures between arms at either time point. Table 4 shows that at 12 -month follow-up intervention arm families were significantly more likely than control arm families to have a bath hot tap water temperature of $46^{\circ} \mathrm{C}$ or below and be satisfied with the temperature. They were significantly less likely to report their bath hot tap water as being too hot and to check the bath water temperature for every bath.

Few families were unhappy with their bath hot tap water temperature at 12 -month follow-up (nine (23\%) in the control arm and five (13\%) in the intervention arm). The majority of those that were unhappy $(n=10)$ reported that the temperature was hot or very hot, with only two reporting it was not warm enough. However, secondary outcomes measured only in the intervention arm (table 5) showed that 12 (36\%) families agreed or strongly agreed that their bath water wasn't hot enough and nine $(27 \%)$ that they could not top up the bath with hot water while in the bath. The majority of families in the intervention arm with a TMV were satisfied with the valve and the fitting process and would recommend TMVs to a friend. Seven of the 46 families (15\%) who had TMVs fitted had problems 
with their TMV; four families reported a low water pressure post-TMV fitting, and in three of these cases the problem was not found to be related to the TMV. One TMV was replaced because of malfunctioning, one family reported a leak after installation and one family reported no hot water from their hot bath tap and the valve was cleaned.

Table 1 Characteristics of participants at baseline, by treatment $\operatorname{arm}(\%)$

\begin{tabular}{lcc}
\hline Characteristics & Intervention arm (n=62) & Control arm (n=62) \\
\hline $\begin{array}{l}\text { Mother completed } \\
\text { questionnaire }\end{array}$ & $57(91.9)$ & $58(93.6)$ \\
$\begin{array}{l}\text { Single adult household } \\
\text { Number of children in the home }\end{array}$ & $40(64.5)$ & $47(75.8)$ \\
1 & $29(46.8)$ & \\
2 & $21(33.9)$ & $25(40.3)$ \\
3 or more & $12(19.4)$ & $26(41.9)$ \\
Age respondent left full-time education & $11(17.7)$ \\
$\leq 16$ & $38(73.1)[10]$ & $43(72.9)[3]$ \\
$17-18$ & $11(21.2)$ & $12(20.3)$ \\
19 plus & $3(5.8)$ & $4(6.8)$ \\
Respondent is a qualified & $4(6.7)[2]$ & $6(9.8)[1]$ \\
plumber & & \\
Number of adults in paid employment & \\
0 & $39(65.0)[2]$ & $40(65.6)[1]$ \\
1 & $16(26.7)$ & $17(27.9)$ \\
$\geq 2$ & $5(8.3)$ & $4(6.6)$ \\
Family receives state & $50(82.0)[1]$ & $56(90.3)$ \\
benefits & & \\
Ethnic group of respondent & & $54(88.5)[1]$ \\
White Scottish & $54(88.5)[1]$ & $3(4.9)$ \\
White other & $1(1.6)$ & $1(1.6)$ \\
Asian & $0(0)$ & $3(4.9)$ \\
Black African & $6(9.8)$ & \\
\hline
\end{tabular}

[]Missing values
Families who did not have any follow-up water measurements either because their properties could not be accessed or because they had been excluded did not differ significantly on any baseline characteristics from those who did have follow-up hot water measurements. Compared to those lost to follow-up, families who completed the follow-up questionnaire were significantly more likely to be happy with their bath hot water temperature $(70 \%$ vs $45 \%$, difference between percentages $(25 \%, 95 \%$ CI $7 \%$ to $42 \%)$ and their water flow at baseline $(50 \%$ vs $30 \%$, difference between percentages $20 \%$, $95 \%$ CI $3 \%$ to $38 \%$ ) and significantly less likely to be receiving state benefits $(81 \%$ vs $95 \%$, difference between percentages $-14 \%, 95 \%$ CI $-25 \%$ to $-4 \%$ )

\section{DISCUSSION}

\section{Principal findings}

TMVs fitted in the homes of families in disadvantaged communities and accompanying educational leaflets are effective in reducing bath hot tap water temperature to the current recommended 'safe' level for at least 12 months post-installation. Most families were satisfied with the temperature and speed of flow of their hot bath water after fitting, and with the fitting process. Those with a TMV were significantly less likely to check the bath temperature of every bath, but we did not find a negative effect on other safety practices.

\section{Strengths and weaknesses of the trial}

As the first randomised controlled trial to assess the effectiveness of TMVs and accompanying educational leaflets in a severely disadvantaged population, with a small proportion of families from minority ethnic groups our findings should be generalisable to similar communities in the UK. Generalising our findings to all families with young children in social housing should be undertaken with caution as it has not been possible for us to estimate our recruitment

Table 2 Bath hot tap water temperature, satisfaction with water temperature and bath time safety practices at baseline, by treatment arm (\% unless specified)

\begin{tabular}{|c|c|c|}
\hline Temperature, acceptability and safety practices & Intervention arm & Control arm \\
\hline Temperature & $n=23$ & $n=27$ \\
\hline Hot bath tap water temperature (median $\left.{ }^{\circ} \mathrm{C}(\mathrm{IQR})\right)$ & $55.0(54.0-58.0)$ & $58.0(55.0-62.0)$ \\
\hline Bath hot tap water $\leq 46^{\circ} \mathrm{C}$ & $0(0.0)$ & $0(0.0)$ \\
\hline Sink hot tap water temperature (median $\left.{ }^{\circ} \mathrm{C}(\mathrm{IQR})\right)$ & $55.0(54.0-58.0)$ & $58.0(54.0-63.0)$ \\
\hline Satisfaction (number (\%)) & $n=62$ & $n=62$ \\
\hline Very happy or happy with bath hot tap water temperature & $39(62.9)$ & $37(59.7)$ \\
\hline \multicolumn{3}{|l|}{ Bath water is: } \\
\hline Very hot-need to add a lot of cold water to the bath & $41(67.2)[1]$ & $38(61.3)$ \\
\hline Hot—need to add some cold water to the bath & $19(31.2)$ & $24(38.7)$ \\
\hline Warm enough — don't need to add any cold water to the bath & $1(1.6)$ & $0(0.0)$ \\
\hline Not very warm—not warm enough to bath in & $0(0.0)$ & $0(0.0)$ \\
\hline Very happy or happy with speed of bath hot tap water flow & $29(46.8)$ & $24(38.7)$ \\
\hline \multicolumn{3}{|l|}{ Safety practices } \\
\hline Runs bath using cold water first & $2(3.2)$ & $9(14.8)[1]$ \\
\hline Bath water temperature checked for every bath & $54(88.5)[1]$ & $54(88.5)[1]$ \\
\hline Bath is only run by adult & $62(100.0)$ & $59(95.2)$ \\
\hline Child bath time always supervised by adult & $57(91.9)$ & $57(93.4)[1]$ \\
\hline Child usually gets in bath after water has been run & $61(98.4)$ & $61(98.4)$ \\
\hline Child has been left alone in the bath & $27(43.6)$ & $13(21.0)$ \\
\hline Child has been left alone in bathroom while bath is running & $19(30.7)$ & $12(19.4)$ \\
\hline
\end{tabular}

[]Missing values. 
rate among families with young children owing to a lack of information on households containing children in GHA records. Furthermore, our findings may not be generalisable to families who are required to pay the costs of TMV fitting. We also cannot assume that the levels of uptake of TMVs, satisfaction and problems with TMVs found in our

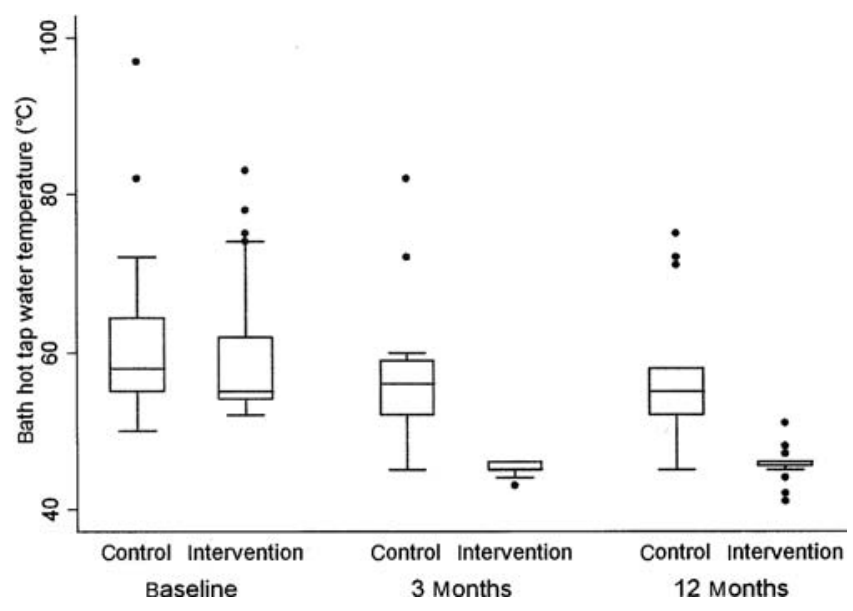

Figure 2 Box plot showing the distribution of bath hot tap water temperatures by treatment group at baseline, 3-month and 12-month follow-up. The bottom and top of the boxes represent the 25th and 75th percentiles, the line in the box is the median. The lines drawn from the box indicate the range, and outlying values are indicated separately. trial would necessarily be replicated in the wider population. Furthermore, our trial was undertaken with one large social housing provider having potentially greater access to resources, skills and economies of scale. Smaller housing providers may find implementing TMVs more difficult.

Just over $25 \%$ of participants were lost to follow-up, mainly as a result of household moves. However, high follow-up questionnaire response rates and the required number of follow-up temperature measurements were achieved and sensitivity analyses suggest findings for the primary outcome are unlikely to be biased by losses to follow-up. Those lost to follow-up for secondary outcome measures were significantly less happy with their bathwater temperature and water flow at baseline than those continuing in the trial, hence satisfaction with hot water temperature and water flow at follow-up may have been lower than we have reported, in both treatment arms.

As with many public health interventions it was not possible to blind participants and plumbers to treatment arm allocation. Additionally, the analyst was able to correctly guess the treatment arm allocation for most participants for the primary outcome, effectively unblinding the analysis.

Our trial was not adequately powered to detect a reduction in the incidence of bath tap water scalds, and a very much larger trial would be required to do this. However, we have shown that TMVs are effective at maintaining a bath hot tap water temperature at or below $46^{\circ} \mathrm{C}$, and water at this temperature would take more than 9 minutes to cause a partial thickness burn, ${ }^{6}$ hence temperature is likely to be a good proxy measure for bath tap water scalds.

Table 3 Primary outcome measures at 3-month and 12-month follow-up by treatment arm

\begin{tabular}{|c|c|c|c|c|}
\hline \multirow{2}{*}{$\begin{array}{l}\text { Outcome measure } \\
3 \text { Months }\end{array}$} & \multicolumn{4}{|c|}{ Median temperature ${ }^{\circ} \mathrm{C}$ (IOR) } \\
\hline & Intervention arm $(n=15)$ & Control arm $(n=15)$ & Difference between medians (95\% CI) & p Value \\
\hline Bath hot tap water temperature* & $45.0(45.0-46.0)$ & $56.0(52.0-59.0)$ & $-11.0(-14.3$ to -7.7$)$ & $<0.001$ \\
\hline $\begin{array}{l}\text { Change in bath hot tap water temperature from } \\
\text { baseline to } 3 \text { months } \dagger\end{array}$ & $-9.0(-16.0$ to -8.0$)$ & $-1.0(-7.0$ to 1.0$)$ & $-8.0(-13.3$ to -2.7$)$ & $<0.001$ \\
\hline Sink hot tap water temperature* & $54.0(53.0-56.0)$ & $54.0(51.0-58.0)$ & $0.0(-3.5$ to 3.5$)$ & 0.74 \\
\hline $\begin{array}{l}\text { Change in sink hot tap water temperature from } \\
\text { baseline to } 3 \text { months } \dagger\end{array}$ & $0.0(-3.0$ to 0.0$)$ & $-2.0(-7.0$ to 1.0$)$ & $2.0(-2.0$ to 6.0$)$ & 0.53 \\
\hline $\begin{array}{l}\text { Bath hot tap water temperature-accounting for } \\
\text { missing values } \ddagger\end{array}$ & $46.0(45.0-54.3)$ & $56.5(52.8-58.3)$ & $-10.5(-15.1$ to -5.9$)$ & $<0.001$ \\
\hline $\begin{array}{l}\text { Sink hot tap water temperature-accounting for } \\
\text { missing values } \ddagger\end{array}$ & $54.5(53.0-55.3)$ & $55.0(51.8-58.0)$ & $-0.5(-3.4,2.4)$ & 0.58 \\
\hline 12 Months & Intervention arm $(n=16)$ & Control arm $(n=15)$ & Difference between medians (95\% CI) & p Value \\
\hline $\begin{array}{l}\text { Change in sink hot tap water temperature from } \\
\text { baseline to } 12 \text { months } t\end{array}$ & $-4.5(-8.8$ to -0.3$)$ & $-3.0(-6.0-2.0)$ & $-1.5(-6.8,3.8)$ & 0.44 \\
\hline Accounting for missing values at 12 months & Intervention arm $(n=26)$ & Control arm $(n=27)$ & Difference between medians (95\% CI) & p Value \\
\hline $\begin{array}{l}\text { Bath hot tap water temperature-accounting for } \\
\text { missing values } \ddagger\end{array}$ & $46.5(46.0-55.0)$ & $58.0(53.0-60.0)$ & $-11.5(-15.8$ to -7.2$)$ & 0.001 \\
\hline $\begin{array}{l}\text { Sink hot tap water temperature—accounting for } \\
\text { missing values } \ddagger\end{array}$ & $55.0(52.8-60.0)$ & $58.0(53.0-62.0)$ & $-3.0(-5.0$ to 1.0$)$ & 0.15 \\
\hline
\end{tabular}

All participants were analysed as randomised regardless of the intervention received.

${ }^{*}$ Analyses include only participants with follow-up temperature measurements.

†The median baseline temperature for the treatment arm was used where families did not have water temperature measured at baseline.

¥Missing follow-up water temperatures were replaced with baseline values, or where water temperature was not measured at baseline, they were replaced with the

median baseline temperature for the treatment arm. 
Table 4 Secondary outcome measures at 12-month follow-up by treatment arm (percentage)

\begin{tabular}{|c|c|c|c|}
\hline Outcome measure & $\begin{array}{l}\text { Intervention arm with water } \\
\text { temperature measurement }(n=16)\end{array}$ & $\begin{array}{l}\text { Control arm with water } \\
\text { temperature measurement }(n=15)\end{array}$ & Relative risk $(95 \% \mathrm{CI})$ \\
\hline Bath hot tap water $\leq 46^{\circ} \mathrm{C}$ & $13(81.3)$ & $2(13.3)$ & 6.09 (1.64 to 22.62$)$ \\
\hline Satisfaction with water temperature and flow speed & Intervention arm responders $(n=40)$ & Control arm responders $(n=40)$ & Relative risk (95\% CI) \\
\hline Very happy or happy with bath hot tap water temperature & $32(82.1)[1]$ & $23(57.5)$ & $1.43(1.05$ to 1.93$)$ \\
\hline \multicolumn{4}{|l|}{ Bath water is: } \\
\hline Very hot-need to add a lot of cold water to the bath & $7(18.0)(1)$ & $22(55.0)$ & $0.33(0.16 \text { to } 0.68)^{*}$ \\
\hline Hot—need to add some cold water to the bath & $16(41.0)$ & $18(45.0)$ & \\
\hline Warm enough-don't need to add any cold water to the bath & $14(35.9)$ & $0(0.0)$ & \\
\hline Not very warm—not warm enough to bath in & $2(5.1)$ & $0(0.0)$ & \\
\hline Very happy or happy with speed of bath hot tap water flow & $24(61.5)[1]$ & $18(45.0)$ & $1.37(0.90$ to 2.09$)$ \\
\hline \multicolumn{4}{|l|}{ Safety practices } \\
\hline Runs bath using cold water first $\dagger$ & $5(12.5)$ & $11(27.5)$ & 0.55 (0.22 to 1.39$)$ \\
\hline Bath water temperature checked for every bath & $32(84.2)[2]$ & $40(100.0)$ & $0.84(0.73$ to 0.97$)$ \\
\hline Bath is only run by adult & $38(95.0)$ & $38(95.0)$ & $1.00(0.90$ to 1.11$)$ \\
\hline Child bath time always supervised by adult & $32(82.1)[1]$ & $34(85.0)$ & $0.97(0.79$ to 1.17$)$ \\
\hline Child usually gets in bath after water has been run & $39(97.5)$ & $39(97.5)$ & $1.00(1.00$ to 1.00$)$ \\
\hline Child has been left alone in the bath $t$ & $13(32.5)$ & $8(20.5)[1]$ & $1.11(0.51$ to 2.41$)$ \\
\hline Child has been left alone in bathroom while bath is running $\dagger$ & $12(30.8)[1]$ & $9(22.5)$ & $1.28(0.62$ to 2.68$)$ \\
\hline
\end{tabular}

[]Missing values.

${ }^{*}$ Compares very hot to other responses.

tAdjusted for baseline value.

Table 5 Satisfaction with the TMV and fitting process at 12-month follow-up

\begin{tabular}{|c|c|c|c|}
\hline & \multicolumn{3}{|c|}{ Intervention arm responders with TMV fitted } \\
\hline & No (total $=34$ ) & $\%$ & $95 \% \mathrm{Cl}$ \\
\hline \multicolumn{4}{|l|}{ Satisfaction with TMV and fitting process } \\
\hline Would recommend TMV to a friend & $28[2]$ & 87.5 & 71.0 to 96.5 \\
\hline Would not be happy if kitchen and bath hot tap water were same temperature & $23[1]$ & 69.7 & 51.3 to 84.4 \\
\hline Have tried to adjust TMV temperature & 0 & 0.0 & 0.0 to 10.3 \\
\hline Information about TMV was easy to understand (if received) & 26 & 100.0 & 86.8 to 100.0 \\
\hline Information helpful to run bath after TMV fitted (if received) & 20 & 76.9 & 56.4 to 91.0 \\
\hline Fitting the TMV didn't make much mess & $30[1]$ & 90.9 & 75.7 to 98.1 \\
\hline Fitting the TMV didn't damage the bathroom & $27[1]$ & 81.8 & 64.5 to 93.0 \\
\hline Plumbers came at time that suited the family & $31[1]$ & 93.9 & 79.8 to 99.3 \\
\hline Fitting the TMV took longer than expected & 10 & 29.4 & 15.1 to 47.5 \\
\hline Doesn't take longer to run bath & $22[2]$ & 68.8 & 50.0 to 83.9 \\
\hline Easier to control bath water temperature & $29[2]$ & 90.6 & 75.0 to 98 \\
\hline Bath water isn't hot enough & $12[1]$ & 36.4 & 20.4 to 54.9 \\
\hline TMV needs too much maintenance & $1[2]$ & 3.1 & 0.1 to 16.2 \\
\hline Can no longer top up bath with hot water while in the bath & $9[1]$ & 27.3 & 13.3 to 45.5 \\
\hline Keeps forgetting needs to run bath in different way & $3[3]$ & 9.7 & 2.0 to 25.8 \\
\hline
\end{tabular}

[]Missing values.

TMV, thermostatic mixing valve.

\section{Comparisons with previous research}

We found higher levels of satisfaction with TMVs than a previous study, possibly because $95 \%$ of valves in the earlier study failed. ${ }^{24}$ We are not aware of any published studies reporting the impact of TMV fitting on bath time safety practices.

\section{Implications for injury prevention practice and further research}

Our trial demonstrated that TMVs and accompanying educational leaflets are effective in reducing bath hot tap water temperatures and are acceptable to families. TMVs may benefit a wider population than that used in our trial, 
especially older people and those with disabilities. The current amendment to English building regulations which relate to new build homes or major refurbishments such as adding a bathroom as part of an extension is likely to protect a small proportion of the population and to disproportionately protect more affluent members of the community, potentially widening inequalities in thermal injuries. Housing providers should consider fitting $T M V s$ in their properties and legislators should consider requiring the fitting of TMVs as part of bathroom refurbishments, such as those installing new baths, which may not be covered by the current amendments to building regulations. We did not find the educational leaflets used as part of the intervention improved bath time safety practices, and the intervention group were less likely to test bath water temperature at follow-up than control families. Further research is needed to explore ways of improving bath time safety practices. TMVs have an in-built safety mechanism to cut off the flow of hot water to prevent scalding in the event of a disruption to the cold water supply. Hence, even if families are less likely to test bath water temperature, this should only increase the risk of a scald if there is a simultaneous disruption to the cold water supply and the TMV malfunctions.

As always, the limitations of a single trial must be borne in mind when considering wider scale implementation of its findings. Wider scale implementation should be accompanied by surveillance and monitoring, including programme components; TMV uptake; tap water temperatures over a longer time period; satisfaction, acceptability and TMV problems; maintenance requirements and impact on other bath time safety practices. Experience with other injury prevention initiatives suggests a range of promotional activities such as media campaigns, incentives and education can be beneficial before implementing legislation. ${ }^{25} \mathrm{~A}$ similar approach may be needed for successful wide scale implementation of TMVs. Finally, cost is a frequently cited argument against fitting $\mathrm{TMVs},{ }^{26}$ and we are conducting an economic evaluation of this trial and findings will be presented elsewhere.

Acknowledgements The authors thank the study participants, East End Child Safety Project workers for their advice on questionnaire design and help with recruiting participants; Professor David Stone, University of Glasgow, for his support throughout the project and comments on the paper for submission; PACT team (Parents and Children Together) for help with recruiting participants; Jim Sodden, of the GHA for facilitation of the study within GHA; Angela McMurran, Bob McGuire, Charlie Thomas, Janet McDonald, Jannette Rawls, Linda Neil of the Local Housing Organisations for facilitating the study within their locality; Alan Skimins and the plumbers of City Building LLP (Glasgow) for coordination and fitting of TMVs, tap water measurements and liaison with Glasgow Housing Association Central Repairs team; Michelle Hubbard and Rose Clacy, members of the Consumer Research Advisory Group at Nottinghamshire County Teaching PCT for development of the study invitation letter and information leaflet; Angus Horne of Horne Engineering for advice and demonstration of the workings of TMVs; Brian Hancock and John Slater, Nottinghamshire County Teaching PCT, for design of the bath tap hanger and study information leaflet; Mark Stevenson of The Scottish Burned Children's Club for facilitating access to a parent of a child with a bathwater scald injury and to the parent for providing the real life story for the study information leaflet.

Funding National Institute for Health Research, Accidental Injury Prevention Research Initiative (001/0009). The final study design, data collection and analysis, interpretation of results and paper writing was the sole responsibility of the authors. The views and opinions expressed in this paper do not necessarily reflect those of the funding body.

Competing interests $\mathrm{MH}$ is an employee of the Child Accident Prevention Trust (CAPT) which is a registered charity. 'INTA' a TMV manufacturer has previously sponsored a CAPT publication. There is the possibility that CAPT could benefit in the future by gaining sponsorship for other publications from TMV manufacturers.

Contributors DK had the original idea for the study, obtained funding, undertook analyses and drafted the paper. JS, LG, CC, MH, ET and CP obtained Department of Health funding and helped with drafting of the paper. JS, CC and SS helped with analyses. NH obtained funding from Glasgow Housing Association and helped with drafting the paper. DR obtained funding from Greater Glasgow and Clyde NHS and helped with drafting the paper. DM, RM, GO, JR and SS helped with drafting the paper. All authors read and approved the final manuscript.

Ethics approval Nottingham 1 NHS research ethics committee (reference number 05/02403/37)

Provenance and peer review Not commissioned; externally peer reviewed.

\section{REFERENCES}

1. Department of Trade and Industry. Consumer safety research: burns and scalds accidents in the home. London: DTI, 1999.

2. Hippisley-Cox J, Groom L, Kendrick D, et al. Cross sectional survey of socioeconomic variations in severity and mechanism of childhood injuries in Trent 1992-7. BMJ 2002;324:1132

3. Cerovac S, Roberts AH. Burns sustained by hot bath and shower water. Burns 2000;26:251-9.

4. Yeoh C, Nixon JW, Dickson W, et al. Patterns of scald injuries. Arch Dis Child 1994;71:156-8.

5. Stephen FR, Murray JP. The prevention of hot tap water burns - a study of electric immersion heater safety. Burns 1991;17:417-22.

6. Feldman KW. Help needed on hot water burns. Pediatrics 1983;71:145-6.

7. Child Accident Prevention Trust. Scarred for life. Preventing bath water scalds in the home. Discussion paper. Armagh: CAPT, 2002.

8. Katcher ML, Landry GL, Shapiro MM. Liquid-crystal thermometer use in pediatric office counseling about tap water burn prevention. Pediatrics 1989;83:766-71.

9. Katcher ML. Prevention of tap water scald burns: evaluation of a multi-media injury control program. Am J Public Health 1987;77:1195-7.

10. Webne S, Kaplan BJ, Shaw M. Pediatric burn prevention: an evaluation of the efficacy of a strategy to reduce tap water temperature in a population at risk for scalds. J Dev Behav Pediatr 1989;10:187-91.

11. Waller AE, Clarke JA, Langley JD. An evaluation of a program to reduce home hot tap water temperatures. Aust J Public Health 1993;17:116-23.

12. Kendrick D, Coupland C, Mulvaney C, et al. Home safety education and provision of safety equipment for injury prevention. Cochrane Database Syst Rev 2007;1:CD005014.

13. Erdmann TC, Feldman KW, Rivara FP, et al. Tap water burn prevention: the effect of legislation. Pediatrics 1991;88:572-7.

14. Department of Communities and Local Government. Enhanced Hot Water Safety and Efficiency Measures for All New Homes. http://www.communities. gov.uk/news/corporate/1230815 (Accessed 25 May 2009).

15. European Child Safety Alliance. Child Safety Strategy: Preventing Unintentional Injuries to Children and Young People in Scotland, 2007.

16. de Caestecker L. A Call to Debate: A Call to Action. A Report on the Health of the Population of NHS Greater Glasgow and Clyde 2007-2008. Glasgow: NHS Greater Glasgow and Clyde, 2008.

17. Edwards $\mathbf{P}$, Roberts I, Clarke M, et al. Methods to increase response rates to postal questionnaires. Cochrane Database Syst Rev 2007,2:MR000008.

18. StatsDirect statistical software [program]. 2.5.5 version. Altrincham, Cheshire: StatsDirect, 2006.

19. Georgieff K, Maw C. The Wakefield district burns and scalds prevention project. Wakefield: Wakefield MDC, Health Development Unit, 2004

20. Child Accident Prevention Trust. Factsheet: bath water scalds. London: Child Accident Prevention Trust, 2002.

21. Hollander M, Wolfe DA. Nonparametric statistical methods. 2nd edn. New York, USA: John Wiley and Sons, 1999.

22. STATA for Windows [program]. 8 version. College Station, Texas, USA: STATA, 2003

23. Fergusson D, Aaron SD, Guyatt G, et al. Post-randomisation exclusions: the intention to treat principle and excluding patients from analysis. $B M J$ 2002;325:652-4.

24. Fallat ME, Rengers SJ. The effect of education and safety devices on scald burn prevention. J Trauma 1993;34:560-3; discussion 563-4.

25. Karkhaneh M, Kalenga JC, Hagel BE, et al. Effectiveness of bicycle helmet legislation to increase helmet use: a systematic review. Inj Prev 2006;12:76-82.

26. House of Commons Hansard Debates for 24 June. Mary Creagh House of Commons debate on Part $\mathrm{G}$ of English Building Regulations. London: The Stationery Office, 2008. http://www.parliament.the-stationery-office.com/pa/ cm200708/cmhansrd/cm080624/halltext/80624h0008.htm (accessed May 2009). 